\title{
Social and Emotional Challenges Encounter Jordanian Parents of Children with Autism Spectrum Disorder
}

\author{
Dr. Mu'tasem M. al-Masa'deh'
}

\author{
Dr. Najati A.Younis ${ }^{1}$
}

\author{
Dr. Nawaf S. al-Zyoud \\ Dr. Moayyad A. Homidi² \\ ${ }^{1}$ Special Education Department, \\ Queen Rania Faculty for Childhood, \\ The Hashemite, University, Zarqa, Jordan \\ ${ }^{2}$ Special Education Department, Education College, \\ King Abdul-Aziz University, Jeddah, Saudi Arabia
}

DOI: https://doi.org/10.36941/jesr-2020-0118

\section{Abstract}

The current study aims to identify daily social and emotional challenges encountered by parents of children with Autism Spectrum Disorder (ASD) and its relation to some demographic variables. The study sample consists of 223 parents whose children having a diagnosis of ASD and receiving services at special education institutions in Amman, the capital city of Jordan. A validated scale was developed to measure social and emotional challenges. Findings revealed that while the most common social challenges were lacking social support, anger and aggression were the parents' dominant emotional challenges in this study. The association between the severity of ASD and the level of challenges was positive, whereas it was negative between household income and challenges. Parents of girls with ASD tended to experience a higher level of challenges.

Keywords: autism spectrum disorder, emotional challenges, social challenges, parents

\section{Introduction and Background}

Special education literature indicates that families have a significant role in developing their social and behavioral children's development, and this role is more substitutional if the child has a disability (Siklos \& Kerns, 2006). However, giving birth to a child with a disability is a remarkable turn in the family function. It has a wide range of extraordinary influences, including family social, emotional, and financial life (Sabah \& Mansory, 2013). These burdens may commence appearing after the disability being diagnosed (Zaareer, 2009).

Autism Spectrum Disorders (ASD) refer to a group of developmental disorders that affect intellectual functions include social interaction, communication, and behavior. Wiggins et al. (2019, p.1) defined autism as "a developmental disability that affects social communication and behavior development and is typically recognized in the first few years of life". Children with ASD have several unique characteristics, such as insufficient ability to communicate with others, developmental delays 
in receptive and expressive language, and stereotypic and restricted behaviors (Al-Zoriqat, 2004). According to Hall and Graff (2011), children with ASD respond to things rather than react to individuals, disturbed by any change in their environment, restricted interests, and repetitive behaviors, words, and phrases. However, children with ASD's characteristics mentioned above complicate familial relationships and responsibilities (Hall and Graff, 2011).

Caring for a child with ASD is a challenging duty as it requires several demanding issues, from their families, including meeting the children's needs and responding to other typical daily responsibilities (Alpern \& Zager, 2007). For some families, the existence of a child with ASD is a major source of difficulties and psychological burdens (Luterman, 2004). According to Alpern and Zager (2007), disability is one of the significant fateful challenges the families encounter since it has a lasting effect on their whole members and functions. Several studies indicated that parents and siblings of children with ASD have a higher level of depression and stress. They suffer from difficulties in social adjustment and dysfunction of their social and emotional organization regardless of their childhood developmental disorders (Ilias et al., 2018; Nora, 1991; Yahya, 2009; Zaareer, 2009). Further, raising a child with ASD influences spousal relationships and creates conflict among family members (Hyassat, 2013; Mclinden, 2005).

\subsection{Disability as a source of social and emotional difficulties}

Families of children with disabilities often experience more challenges and stresses than families of typically growing children. For most children with disabilities, the stress begins when they suspect that their child has a developmental delay. They are struggling then to obtain an accurate diagnosis. Disclosing the disability could be the worst news that the families hear; it is often an unwanted and disappointing occasion for all family members (Hall and Graff, 2011; Kumar, 2008). Families may encounter various difficulties while they attempt to cope with their children with disabilities; these difficulties include sensitive parental emotions, disappointment, uncertainty, inappropriate family members' interrelationship, lack of mutual support, and feeling of isolation (AL-Dadi, 2009; Hanafi, 2007; Hyassat, 2013).

\subsection{ASD as a source of social and emotional difficulties}

Apparently, for families of ASD children, the stressors mentioned above are more intense, making their lives more difficult and creating daily difficulties and hindering them (Sevim, 2007); this is specifically true for meeting the daily routine of children with ASD needs, such as toileting and feeding requirements. Accordingly, some parents may become more vulnerable to anxiety, depression, and stress (Matter, 2006) and experience many emotional, social, and psychological problems (Li, Vestrgaard \& Obel, 2009). Families of ASD suffering more challenges resulted from their children's behavioral difficulties that combined with ASD symptoms (Bashir, Bashir \& Ahmad, 2014). ASD has several impacts on social, emotional, and financial family life, such as the relationship between parents and siblings, family adjustment, and functions (Greef \& Walt, 2010).

Usually, parents of ASD spend their most time maintaining their child's requirements; they may feel exhausted and have no free time to participate in social activities (Ilias et al., 2018). Sometimes, ASD children's inability to do their self-daily life skills and their cognitive dysfunction trigger many challenges among families in most cases (Al-Zahrani, 2008; Zaareer, 2009). These challenges may contribute to a series of unbearable psychological problems that affect the families' quality of life, severely feel isolated and lonely (Bashir et al., 2014; Hanafi, 2007). All family members of ASD children could be impacted by living with a child with ASD. Kumar (2008) confirmed that raising a child with ASD is not a simple family mission.

By and large, caring for a child with ASD may lead to instability relationships among family members; this may be because of the constant burden that the ASD entails, most of the family members will have extra responsibilities toward the child with ASD. This may lead to a conflict inside the family; 
for example, some parents exchange blames themselves or others to cause their child's disorder (Obrien, 2013). Further, some families could not manage their conflicts and emotions well, and therefore, they encounter chronic challenges in dealing with their children with ASD and their members (Lee, 2009).

\subsection{Literature Review}

Several studies have been conducted investigating families of children with ASD. Most of these studies concern the challenges families face while living with children with ASD, including stress, social, emotional, and financial difficulties. For example, Al-Nawasreh (2017) found that the level of psychological loneness among families of ASD children in north Jordan was high. Bosha'raeh and Taher (2017) found that while mothers of ASD children had higher psychological stress than their fathers, there was a positive relationship between psychological stress and families' compatibility with ASD. Similarly, Al-Khaldi (2016) reported that $70 \%$ of his sample, which were families of ASD children, had difficulties in their social relations, while $80 \%$ were struggling with challenging family conditions.

Similar results were found in China; Ting, Yiting, and Ghunli (2018) surveyed 263 parents of children with ASD investigating the challenges of bringing up a child with ASD. The parents were highly stigmatized and depressed; they experienced various feelings, such as bereavement, shame, low self-esteem, and inability to adapt. While family income was negatively correlated with the challenges, Chinese parents of ASD encountered, their educational level had no influence (Ting, Yiting \& Ghunli, 2018).

Hyassat (2013) interviewed 54 parents of children with disabilities. Those children had different types of disabilities and were receiving early intervention services in Jordan. The parents identified various internal and external challenges, such as oppression and discrimination, constant distress, isolation, and social stigma. Meanwhile, the parents reported significant problems in the availability and accessibility of Jordan's social and emotional support systems (Hyassat, 2013). Zaareer (2009) stressed that the most common sources of psychological stress among parents of children with ASD were fear for their children's future, burdens of caring for their children, and their children deficiency in most developmental areas included daily life activities, cognitive abilities, and adaptive behaviors. In Phetrasuwan and Miles' (2009) study, which was based on interviewing mothers of children with ASD, they argued that mothers' psychological stresses resulted from several factors such as difficulties in managing their children behaviors in public places, anxieties, worries, disobeyed conducts, nervousness, and insufficient verbal communication skills.

Much of previous studies on caring for children with ASD have frequently indicated that parents experienced stress, depression, family disputes, and conflicts, and dealing with others outside the family (Baker, Seltzer \& Greenberg, 2011; Hastings, 2003; Gray, 2002; Jones, Hasting, Totiski, Keane \& Rhule, 2014; Kelly, Garnett, Attwood \& Peterson, 2008; Malijaars, Boonen, Lambrechts, Leeuwen \& Noens, 2014; Rozonova, 2008). Likewise, sisters and brothers of children with ASD reported similar challenges (Hughes \& Watson, 2018; Mascha \& Boucher, 2006; Rao \& Beidel, 2009). Further research has compared the psychological stress between families of children with disabilities (including ASD) and families of children with non-disabilities; the results of all these studies were in agreement that families of children with disabilities had a higher level of stress (Ilias et al., 2018; Gupta \& Singhal, 2005; Kersh et al. 2006).

\subsection{Jordanian Context}

There are no accurate data on the prevalence of disability in Jordan where the rates range from an official rate $(2.7 \%)$ to estimated one (13\%) (Thompson, 2018) and the prevalence of ASD in 2010 was determined by (0. 05\%) of the total disabilities ( $\mathrm{Al} \mathrm{Tal,} \mathrm{Al} \mathrm{Jawaldah} \mathrm{\&} \mathrm{Banat,} \mathrm{2016).} \mathrm{However,} \mathrm{Jordan} \mathrm{is}$ a conservative country with high Islamic and Arabic values. These values reflect the process of understanding the disability, interpreting disability, and responding to having a disabled child in 
Jordanian families. Some Jordanian families understand disability as a curse while there is no available and accurate data indicating that families consider disability a grace or strength point. Therefore, some families who feel ashamed of having a disabled child tend to hide their disabled child from the public and be less openly talking about it. This also applies to the parents and siblings who encounter several difficulties due to having a disabled member in the family. Despite increasing evidence of positive formatting attitudes towards disabled children in Jordan (Thompson, 2018), disability and ASD are still being seen as a burden on families and considering ASD children as burdensome and shameful. As a result and unlike western countries, most of the research carried out in Jordan has concentrated on issues relating to measurement and diagnosis, teaching methods, and meeting children's needs rather than seeing disability as a point of strength.

\subsection{Study Statement and Questions}

Undoubtedly, families of children with ASD have to experience several social and emotional challenges. These challenges vary between families according to various factors, such as severity, available services, culture norms, family household income, and available support (Malkosh \& Yahya, 1995). Findings of the existing research acknowledge that parents of children with ASD struggle to maintain appropriate services for their children; they are keen to live a healthy life, but unfortunately, they experience numerous challenges that create stress. For example, some parents exert much effort to make their children with ASD behave adaptively in their local communities to avoid embarrassment and disgrace (Al-Khofash, 2001; Al-Moteri, 2006; Davis \& Carter, 2008). Jellett, Wood, and Seymour (2015) confessed that having a negative effect from raising a child with ASD cannot be denied; this could include physical, emotional, and financial burdens (Cidave, Marcus \& Mandell, 2015).

From the authors' personal experiences, they believe that the maladaptive behaviors conducted by the child with ASD are the primary source of family challenges. They struggle to understand and deal appropriately with their children's behaviors, especially when they live in an area where the needed services are not readily available. Thus, this study hopes to uncover the emotional and social challenges that Jordanian families of children with ASD face, which may, in turn, help in developing disability services and policy. Specifically, the current study tries to answer the following questions:

1. What emotional challenges do families of children with ASD encounter in Jordan?

2. What social challenges do families of children with ASD encounter in Jordan?

3. Are there differences in the encountered challenges among Jordanian families of ASD according to the child's gender, autism severity level, and family household income?

\subsection{Significance of the Study}

This study's results hope to open the door for setting up a unique support system for families of children with ASD in Jordan. This study also may contribute to one or more of the following benefits:

1. Filling the significant gap in the existing literature about the status of Jordanian families of children with ASD as very little research has been published in English.

2. Helping services providers understand families of children with ASD can ultimately sustain the families to cope effectively with their children. This understanding may also support the families to manage their feelings and emotions when faced with the challenges, especially families of recently diagnosed children.

\section{7}

\section{Definition of Terms Used}

Social challenges: can be defined as the challenges that face families in their interrelationship and, or in their social network (Lee, 2009). In this study, the term Social challenges are used to mean the total score of parents' responses on the study instrument that includes three subscales: maladaptive behavior, lack of social support, and lack of social competency. 
Emotional challenges: refer to the difficulties that families encounter in their feelings, worries, fear of the child's future, and sensations (Rozonova, 2008). For this study, emotional challenges are used to mean the total score of parents' responses to the study instrument that includes four subscales: anger and aggression, anxiety, rebellion, and social withdrawal.

Parents of children with ASD: in this study, this term refers to Jordanian parents whose children have been identified as having ASD. Meanwhile, their ASD children received educational services in special education institutions in Amman, Jordan's capital city, in the academic year 2017/2018.

\subsection{Delimitations}

The results of this research cannot generally consider applicable to all families of children with ASD because of the following delimitations:

- Human delimitation: the sample size includes only families from the capital city of Jordan (Amman)

- Spatiotemporal delimitation: this research was conducted in special education institutions serving children with ASD in Amman during the academic year 2017/2018.

- Objectivity delimitation: The psychological properties of the study instrument (include validity and reliability developed by the researcher) are taken into account when generalizing the results.

\section{Methodology}

\subsection{Study Approach}

This study employs a quantitative approach to answer the research questions, utilize questionnaire design, and investigate the challenges facing families of children with ASD in Jordan; this may help policymakers establish support services for those families.

\subsection{Population and Sample}

The study population consisted of all families of children with ASD in Amman, Jordan's capital city. From this population, 223 parents voluntarily agreed to fill in the research instrument after a series of communication processes had been done between the researcher and the parents. Of those parents, 122 were fathers, and 101 were mothers of children with ASD enrolled in different special education institutions. Table (1) describes the study sample.

Table 1: Description of the study sample

\begin{tabular}{|l|l|c|c|}
\hline Variable & Level & Frequency & Percentage \\
\hline \multirow{3}{*}{ Child Gender } & Male & 159 & $71.3 \%$ \\
\cline { 2 - 4 } & Female & 64 & $28.7 \%$ \\
\hline \multirow{3}{*}{ Severity of ASD } & Mild & 61 & $27.4 \%$ \\
\cline { 2 - 4 } & Moderate & 88 & $39.5 \%$ \\
\cline { 2 - 4 } & Severe & 74 & $33.2 \%$ \\
\hline \multirow{3}{*}{ Household Income } & Low & 85 & $38.1 \%$ \\
\cline { 2 - 4 } & Moderate & 92 & $41.3 \%$ \\
\cline { 2 - 4 } & High & 46 & $20.3 \%$ \\
\hline Total & & 223 & $100 \%$ \\
\hline
\end{tabular}




\subsection{Study instrument}

Social and Emotional challenges Scale: To achieve the study aims, a scale was developed by reviewing the literature that related to challenges encounter by families of children with ASD (Al-Emam \& Al-Jwaldeh, 2010; Al-Zoriqat, 2010). Subscales were identified by reviewing the existing scales that employed in the previous research concerning family challenges whose children had a disability (Al-Bodirat, 2006; Alkhofash, 2001; Al-Moteri, 2006; Baker, Seltzer \& Greenberg, 2011; Hastings, 2003; Jones, Hasting, Totiski, Keane \& Rhule, 2014; Gray, 2002; Malijaars, Boonen, Lambrechts, Leeuwen \& Noens, 2014).

The scale consists of two parts: part (a) entails demographic information about the respondent includes child gender, ASD severity, and household income. Part (b) contains 38 items covered two major dimensions that are Social Challenges and Emotional Challenges. The Social Challenges dimension includes three subscales: Maladaptive Behavior (items 1-4), Lack of Social Support (items 610), and Insufficient Social Competence (items 11-15). The second dimension includes four subscales includes Worry (items 12-20), Social withdrawal (items 21-25), Anger and Aggression (items 26-33), and Rebellion (items 34-38). The scale is self-reported items, and the potential parents are asked to rate their feeling using a five-point Likert scale: always (5), often (4), sometimes (3), rarely (2), and never (1). The highest score could be collected at the scale is (190), and the lowest is (38).

\subsection{Psychometric Properties of the Research Instrument}

\subsubsection{First: content validity}

To ensure content validity for the research instrument, ten academic referees working in the Hashemite University and the University of Jordan, who have special education experiences, educational psychology, and educational measurement and assessment, reviewed the initial version of the scale. Those referees were asked to give their opinions on the whole scale, including checking items appropriateness, examining language accuracy, and suitability of the scale overall to achieve the research purposes (Hyassat, Alkhayat\& Alzyoud, 2015). The items were modified based on the reviewers' revisions, and eventually, the scale consisted of 38 items.

\subsubsection{Second: construct validity}

The scale was piloted by 30 parents of children with ASD out of the study sample. The researcher then evaluated a correlation coefficient between the total score and each item. These correlations' coefficient values ranged between (0.52-0.66), which were considered satisfactory as an indicator for internal consistency.

\subsubsection{Third: reliability}

The Test-Retest reliability technique was used to examine the scale's reliability. The scale was refilled in again by the 30 parents two weeks later; the relationship between the two times was statistically measured using Person correlation (o.87). Reliability was also calculated by Chronbach alpha, which was $(0.80)$, and this was reasonable for this study.

\section{Results}

\subsection{The first question: What social challenges do families of children with ASD encounter in Jordan?}

To answer this research question, means and standard deviations were calculated for the data collected on the Social Challenges dimension of the scale. Table (2) shows the means and standard deviation of all items covered in the scale's first dimension. 
Table 2. Means and standard deviations for Social Challenges Dimension ranked in descending order according to their means

\begin{tabular}{|c|c|c|c|c|}
\hline \multicolumn{3}{|c|}{\begin{tabular}{|l|l|l|} 
No. & Rank & Item \\
\end{tabular}} & Mean & SD \\
\hline \multicolumn{5}{|c|}{ First: Maladaptive Behavior } \\
\hline 1 & 1 & People around ignore me as I have a child with ASD & 3.93 & 1.22 \\
\hline 2 & 2 & $\begin{array}{l}\text { The presence of my child with ASD hinder me from helping others to sort their troubles } \\
\text { out }\end{array}$ & 3.93 & 1.20 \\
\hline 3 & 4 & People around are bothered by me because of my child with ASD & 3.60 & 1.27 \\
\hline 4 & 5 & I feel happy when I don't attend social activities conducted by the local community & 3.48 & 1.07 \\
\hline 5 & 3 & My work colleagues taunt me as I have a child with ASD & 3.42 & 1.13 \\
\hline \multicolumn{3}{|c|}{ Total } & 3.67 & .70 \\
\hline \multicolumn{5}{|c|}{ Second: Lack of Social Support } \\
\hline 6 & 10 & When I feel unstable, no one from my family members and friends supports me. & 3.91 & 1.17 \\
\hline 7 & 8 & $\begin{array}{l}\text { I refuse help from my family members and colleagues when I try to sort out my ASD child } \\
\text { problems }\end{array}$ & 3.74 & 1.21 \\
\hline 8 & 6 & I feel comfort when I stay alone & 3.65 & 1.25 \\
\hline 9 & 7 & $\begin{array}{l}\text { I find it challenging to seek help from my family members or friends if I confront a sudden } \\
\text { problem }\end{array}$ & 3.63 & 1.28 \\
\hline 10 & 9 & I feel not accepted nor sympathized by others because I'm a parent of a child with ASD & 3.56 & 1.26 \\
\hline \multirow{2}{*}{\multicolumn{5}{|c|}{ Third: Insufficient Social Competence }} \\
\hline & & & & \\
\hline 11 & 13 & $\begin{array}{l}\text { I find it challenging to fulfill my duties and my child obligations in coordination with my } \\
\text { family members }\end{array}$ & 3.63 & 1.25 \\
\hline 12 & 15 & I conduct nervously when I face troubles with my friends, colleagues, and family members & 3.63 & 1.30 \\
\hline 13 & 11 & I avoid helping my friends and family members if they need me & 3.46 & 1.14 \\
\hline 14 & 12 & I stay away from sharing with my family members and friends their troubles and concerns & 3.32 & 1.32 \\
\hline 15 & 14 & I think my family members feel angry with me as I have a child with ASD & 3.22 & 1.13 \\
\hline \multicolumn{3}{|c|}{ Total } & 3.45 & 0.79 \\
\hline
\end{tabular}

The table; shows the means of social challenges among Jordanian parents of children with ASD ranged between moderate to high (3.22-3.93). Lack of Social Support subscale has the highest mean (3.7) while the item "People around ignore me as I have a child with ASD" has the highest mean (3.93). The lowest mean (3.22) is related to the Insufficient Social Competence Subscale, item "I think my family members feel angry with me as I have a child with ASD."

3.2 The second research question: What emotional challenges do families of children with ASD encounter in Jordan?

To answer the second research question, means and standard deviations were calculated for the data collected on the scale's emotional Challenges dimension. Table (3) shows the means and standard deviation of all items covered, the second dimension of the scale.

Table 3. Means and standard deviations for Social Challenges Dimension ranked in descending order according to their means

\begin{tabular}{|l|l|l|l|l|}
\hline No. & Rank & Item & Mean & SD \\
\hline \multicolumn{2}{|l|}{ Fourth: Worry } & 3.63 & $\mathbf{1 . 3 0}$ \\
\hline 16 & 18 & I have a feeling of gagging and vomiting because of my child actions & 3.43 & $\mathbf{1 . 2 6}$ \\
\hline 17 & 16 & I get a feel of pain in all of my body when I think of my child with ASD & 3.40 & $\mathbf{1 . 4 3}$ \\
\hline 18 & 20 & I suffer from anorexia because of thinking of my child with ASD & 3.35 & $\mathbf{1 . 2 5}$ \\
\hline 19 & 17 & Each time I try to train my child with ASD, I feel pain in my stomach & 3.31 & $\mathbf{1 . 2 2}$ \\
\hline 20 & 19 & I become terrified when I think of the future of my child with ASD & 3.34 & $\mathbf{1 . 1 2}$ \\
\hline \multicolumn{2}{|l|}{ Total }
\end{tabular}




\begin{tabular}{|c|c|c|c|c|}
\hline \multicolumn{3}{|c|}{\begin{tabular}{|l|l|l|} 
No. & Rank & Item \\
\end{tabular}} & Mean & SD \\
\hline \multicolumn{5}{|c|}{ Fifth: Social withdrawal } \\
\hline 21 & 24 & I feel like tense and depressed because of the presence of my child with ASD & 3.67 & 1.46 \\
\hline 22 & 21 & I hate social occasions because of combining my child with ASD & 3.35 & 1.55 \\
\hline 23 & 22 & I get annoyed from talking with others as they ask me about my child case & 3.31 & 1.43 \\
\hline 24 & 23 & I fear to deal with others as I have a child with ASD & 3.22 & 1.53 \\
\hline 25 & 25 & I want to stay alone to think of my child with ASD & 3.13 & 1.45 \\
\hline \multicolumn{3}{|c|}{ Total } & 3.43 & 0.81 \\
\hline \multicolumn{5}{|c|}{ Sixth: Anger and Aggression } \\
\hline 26 & 28 & I hit the land strongly when I fight others & 3.92 & 1.30 \\
\hline 27 & 29 & I break anything to reach my hand & 3.85 & 1.32 \\
\hline 28 & 31 & I use sharp gazes and gestures when I struggle with my family members and friends & 3.85 & 1.32 \\
\hline 29 & 33 & I feel upset and bored because of my child with ASD & 3.71 & 1.22 \\
\hline 30 & 32 & I angrily deal with my colleagues, friends and family members for no logical reason & 3.69 & 1.28 \\
\hline 31 & 30 & I push others aggressively when I leave home or work & 3.68 & 1.32 \\
\hline 32 & 26 & I insult my friends and family members without a logical reason & 3.35 & 1.47 \\
\hline 33 & 27 & I fight my friends and family members without a reasonable reason & 3.12 & 1.39 \\
\hline \multicolumn{3}{|r|}{ - } & 3.65 & 0.79 \\
\hline \multicolumn{5}{|c|}{ Seventh: Rebellion } \\
\hline 34 & 34 & I resist my family members, friends, and everybody who tries to belittle me & 3.73 & 1.23 \\
\hline 35 & 36 & $\begin{array}{l}\text { It is hard to convince me of family members, friends, and colleagues' views that they offer } \\
\text { about my child with ASD }\end{array}$ & $3 \cdot 59$ & 1.23 \\
\hline 36 & 37 & I enjoy arguing with my family members, friends, and colleagues and criticizing them & 3.54 & 1.21 \\
\hline 37 & 38 & I hate fulfilling my work to the optimal and required level & 3.53 & 1.20 \\
\hline 38 & 35 & $\begin{array}{l}\text { I feel thrilled whenever I have a chance to do something that my family members, friends, } \\
\text { and colleagues do not like }\end{array}$ & 3.35 & 1.17 \\
\hline \multicolumn{3}{|c|}{ Total } & 3.55 & 0.77 \\
\hline
\end{tabular}

Like social challenges, it is clear that the means of emotional challenges among Jordanian parents of children with ASD ranged between moderate to high (3.12-3.92). As shown in the table, the Anger and Aggression Subscale has the highest mean (3.65). While the item "I hit the land strongly when I fight others" has the highest mean, the item "I fight my friends and family without reasonable reason" has the lowest mean (3.12). It is worth mentioning that all means' items related to the Emotional Challenges dimension ranged from moderate to high.

3.3 The third research question: Are there differences in the encountered challenges among Jordanian families of ASD according to a child's gender, autism severity level, and family household income?

\subsubsection{Gender of the child with ASD}

To uncover whether the gender of the child affects the encountered challenges, two-independent sample t-test was used. Results revealed that there are significant statistical differences in social and emotional challenges that the parents face in favor of the girl. Table (4) shows the differences in social and emotional challenges among the parents according to the gender of a child with ASD.

Table 4. T-test for examining the differences in the challenges according to the child's gender

\begin{tabular}{|l|c|c|c|c|c|}
\hline Gender & Mean & SD & Means' differences & T & Sig \\
\hline Boy & 131.22 & 19.7 & 12.56 & 4.355 & \multirow{2}{*}{0.00} \\
\hline Girl & 143.78 & 18.9 & 126 \\
\hline
\end{tabular}




\subsubsection{Autism Severity Level}

One-Way ANOVA analysis was conducted to determine the differences in the means of encountered challenges among the Jordanian parents of children with ASD according to the autism severity level Table (5).

Table 5. One-Way Anova analysis of the effect of autism severity level on the encountered challenges

\begin{tabular}{|l|c|c|c|c|c|}
\hline Source of Variance & Sum of square & Degree of Freedom & Means of Square & F & Sig \\
\hline Autism Severity & 9283.721 & 2 & 4641.86 & & \multirow{3}{*}{0.00} \\
\cline { 1 - 4 } Error & 81798.46 & 220 & 371.8112 & \multirow{2}{*}{0.48446} \\
\cline { 1 - 4 } Total & 91082.18 & 222 & & \\
\hline
\end{tabular}

The table shows significant statistical differences attributed to the autism variable's severity where $\mathrm{F}$ value is (12.48446).To determine the source of differences between the three severity levels, the Scheffe Test was carried out. Table 6 shows the source of these differences.

Table 6. Results of Scheffe Test for differences according to autism severity level

\begin{tabular}{|l|c|c|c|c|c|}
\hline Autism severity & Mean & SD & Mild & Moderate & Sever \\
\hline Mild & 124.49 & 18.01 & & $12.940^{*}$ & $15 \cdot 751^{*}$ \\
\hline Moderate & 137.43 & 17.52 & & & 2.811 \\
\hline Sever & 140.24 & $\mathbf{2 2 . 0 9}$ & & & \\
\hline
\end{tabular}

In table 6, it is clear that there are significant statistical differences between mild and moderate autism in favor of moderate, and between mild and severe autism in favor of severing. In contrast, there were no significant statistical differences between moderate and severe autism.

\subsubsection{Household income}

To unfold whether the variable 'household income' effects the encountered challenges among Jordanian parents of children with ASD, the research employed One-Way Anova analysis Table (7).

Table 7. One-Way Anova analysis of the effect of household income on the encountered challenges

\begin{tabular}{|c|c|c|c|c|c|}
\hline Source of Variance & Sum of square & Degree of Freedom & Means of Square & $\mathrm{F}$ & Sig \\
\hline Household income & 2881.449 & 2.00 & 1440.72 & \multirow{3}{*}{3.593614} & \multirow{3}{*}{0.026} \\
\hline Error & 88200.730 & 220.00 & 400.91 & & \\
\hline Total & 91082.179 & 222.00 & & & \\
\hline
\end{tabular}

The table shows significant statistical differences attributed to the household income variable where $\mathrm{F}$ value is (3.593614). To determine the source of differences between the three levels of household income, the Scheffe' Test was carried out. Table 8 shows the source of these differences.

Table 8. Results of Scheffe' Test for differences according to the level of household income

\begin{tabular}{|l|c|c|c|c|c|}
\hline Household income & Mean & SD & Low & Moderate & High \\
\hline Low & 139.20 & 17.86 & & 6.113043 & $8.982609^{*}$ \\
\hline Moderate & 133.09 & 18.13 & & & 2.869565 \\
\hline High & 130.22 & 26.46 & & & \\
\hline
\end{tabular}

The table shows that while there are significant statistical differences between the low and high in favor 
of low, there were no significant statistical differences between moderate and high nor between moderate and low.

\section{Discussion}

It has been argued that "caring for a child with a disability is undeniably time- consuming and can have a dramatic impact on the daily lives of whole families" (Green, 2003, p.1367). The results of this study replicated the results of previous research by showing that social and emotional challenges among parents of children with ASD are prevalent. However, the most common social challenge that parents of children with ASD encounter in Jordan lack social support. This result seems to be a logic where parents are continually facing daily psychological stress, burdens, and disruptions derived from meeting their children's needs with ASD. Hyassat (2013) suggests that Jordanian parents of children with disabilities experience stigma, feeling of isolation, and repudiation. Therefore, it is reasonable to propose that parents want to be supported by formal and informal sources. The current study confirms the results of previous studies such as Al-Nawasreh (2017); he reported that, in north Jordan, parents of children with ASD have a high level of loneliness. Similarly, Al-Khaldi (2016) claims that over 70\% of Jordanian parents of children with ASD having difficulties in their social life; he insists on the importance of supporting them to promote their family well-being.

It can be assumed that lacking social support has contributed to increasing in maladaptive behavior among Jordanian parents of children with ASD; this is evident in this research where the parents experience various negative feeling resulted from unproductive behaviors appeared by children with ASD; this, in, turn complicates the way that the parents interact and deal with others around them. This study confirms the findings of the earlier research, for example, Gray (2008), Kelly, Garnet, and Peterson (2008), and Rozonova (2008).

In terms of emotional challenges, the results show that the parents significantly experience anger and aggression. The amount of depression can interpret this that they daily feel and a sense of helplessness; they continue to experience stressful situations. They disparately attempt to manage their children's lives; the parents try to make differences in their children's development, but unfortunately, their children's abilities do not support parents' desire to alter their actual conditions. Likewise, due to the constant burdens placed on Jordanian parents of children with ASD in this study, they display different emotions such as rebellion, worry, and social withdrawal. Many previous studies suggest that the parents of children with ASD exhibit such feelings (Baker et al., 2011; Jones et al., 2014; Malijaars et al., 2014; Phetrasuwan \& Miles, 2009; Rozonova, 2008; Zaareer, 2009). These emotional challenges may be "generated by complex interactions between internal factors, such as dealing with their children, and external factors such as dealing with individuals outside the family" (Hyassat, 2013, p.63).

The Gender of the child with ASD seems to affect the intensity of challenges that parents encountered. The parents of girls with ASD report more intense social and emotional challenges than the parents of boys with ASD. This may refer to the Arabian cultural context that looks differently at the boys; Arab culture perceives the boy as stronger than a girl. It is seen that females with ASD are more likely to be vulnerable to violence than males, which may increase parental future fears and worries when they no longer around. Part of the Jordanian culture is reported parents feel that they are responsible for their daughters from the cradle to the grave, but sons can survive and manage life affairs. The idea of girls with ASD composes more challenges than a boy does is reported in Nora's (1991) study, where parents of girls with ASD experience a higher anxiety level.

Much of research argue that parents of children with severe ASD are subjected to experience a higher level of distress, anxiety, and depression compared to parents of children with mild or moderate ASD (Al-Farsi, 2016; Gray, 2002; Mclinden, 2005; Padden \& James, 2017; Sikora et al., 2013). This is particularly true among Jordanian parents of children with ASD where the available provision for their children is unreliable and unpredictable. As children with severs ASD are less likely to attain an adequate degree of independence, their parents have to deal with the continuous burden of responsibility, including acting as caregivers, financial support, and physical helper daily life activities. 
Autism severity has been connected to the level of parental psychological distress and unstable family relationships (Mclinden, 2005; Sikora et al., 2013).

It is well documented that caring for a child with a disability requires an ongoing financial burden (Green, 2003; Omar, Ahmed \& Basiouny, 2017; Rogers, 2007). This economic demand is most likely to increase the challenges that Jordanian parents of children with ASD encounter. Therapy and educational services for children with ASD in Jordan are mostly provided by the private sector and are expensive; these services include health care, early intervention, medicines, doctor checks, speech therapy, occupational therapy, and dietary intervention. It is logical to assume that buying this wide range of services is more challenging for the parents whose household income is low, which is reported by the parents in this study. This is consistent with existing literature that confirms that when economic status decreases, psychological distress increases among parents of children with ASD (AlBodirat, 2006; Al-Farsi, 2016; Al-Moteri, 2006; Omar, Ahmed \& Basiouny, 2017; Phetrasuwan \& Miles, 2006).

\section{Conclusion}

This study seeks to identify daily social and emotional challenges facing Jordanian parents of children with ASD. Although it is well documented worldwide (mostly in western countries) that caring for a child with ASD contributes to higher levels of challenges, Jordan's evidence seems to be little where the cultural contexts and disability provision are different. Jordanian parents of children with ASD report a high level of social and emotional challenges associated with their economic status, children's gender, and autism severity. However, this study hopes to help policymakers and service providers overcome the challenges that the parents encounter and enhance the support system; this may, in turn, ultimately lead children with ASD to reach their full potential and help parents, who may well be having a child with ASD, to come to terms with the diagnosis and its implications.

\section{References}

Al Tal, S. M., Banat, S. M., \& Al-Jawaldeh, F. E. (2016). Emotional Problems among Mothers of Adolescents with Autism Disorder. Jordan Journal of Social Sciences, 404(3978), 1-12.

Al-Bodirat, N. (2006) Stress on Brothers of Autistic Children and Its Relationship with Some Personal and Family Variables. Unpublished dissertation. Amman Arab University.

AL-Dadi, G. (2009). Psychological Stress, Marital, and Familial Adjustment among Parents of Disabled Children with different Types and Degrees of Disabilities and certain demographic and social variables. Unpublished dissertation. Umm Al-Qura University.

Al-Emam, M., \& Al-Jwaldeh, F. (2010) Autism ETheory of Mind. Daralthaqafa. Amman. Jordan.

Al-Farsi, O. A., Al-Farsi, Y. M., Al-Sharbati, M. M., \& Al-Adawi, S. (2016). Stress, anxiety, and depression among parents of children with an autism spectrum disorder in Oman: a case-control study. Neuropsychiatric disease and treatment, 12, 1943.

Al-Khaldi, A. (2016) The most important social problems families face in caring for children with autism and ways of treatment and rehabilitation. Allstate Journal, 2 (17), 1-28.

Allik, H., Larsson, J. O., \& Smedje, H. (2006). Health-related quality of life in parents of school-age children with Asperger syndrome or high-functioning autism. Health and quality of life outcomes, 4(1), 1-8.

Al-Moteri, F. (2006) Sources of Psychological Stress on Brothers of Autistic Children and Its Relationship with Some Personal and Family Variable. Unpublished dissertation. Jordan University.

Al-Nawasreh, F. (2017) The Sense Of Psychological Loneliness Among The Families Of Autistic Children And Its Relationship With Some Variables And The Child Impairment Degree. International Interdisciplinary Journal of Education,6(5), 198-21.

Alpern, C. S., \& Zager, D. (2007). Addressing the communication needs of young adults with autism in a collegebased inclusion program. Education and Training in Developmental Disabilities, 42(4), 428-436.

Al-Zahrani, A. (2008). Saudi Family and new changes. Imam Muhammad ibn Saud Islamic University. Riyadh. KSA.

Al-Zoriqat, I. (2004) Autism: Characteristics and Treatment. Dar Wa'el. Amman. Jordan.

Al-Zoriqat, I. (2010) Autism: Diagnosis and Treatment. Dar Wa'el. Amman. Jordan. 
Baker, J. K., Seltzer, M. M., \& Greenberg, J. S. (2011). Longitudinal effects of adaptability on behavior problems and maternal depression in families of adolescents with autism. Journal of Family Psychology, 25(4), 1-16.

Baker, J., Seltzer, M. \& Greenberg, J. (2011). Longitudinal Effects of Adaptability on Behavior Problems and Maternal Depression in Families of Adolescents with Autism. Journal of Family Psychology, 25(4), 601-609.

Bashir, A., Bashir, U., \& Ahmed, Z. (2014). Challenges Faced by families of Autistic International Journal of Interdisciplinary Research and Innovations, 2(1), 64-68.

Bosha'raeh, F., \& Taher, F. (2017) Parental stress and family adjustment of parents of children with autism. Global Libyan Journal, 14 (1), 1-23.

Cidave, Z., Marcus, S., and Mandell, D. (2015). Implications of Childhood Autism for Parental Employment and Earnings. Pediatrics, 129(4), 617-626.

Davis, N. O., \& Carter, A. S. (2008). Parenting stress in mothers and fathers of toddlers with autism spectrum disorders: Associations with child characteristics. Journal of autism and developmental disorders, 38(7), 12781291.

Gray, D. (2002). Ten Years on A Longitudinal Study of Families of Children with Autism. Journal of Intellectual and Developmental Disabilities, 27 (3), 215- 222.

Greeff, A. P., \& Van der Walt, K. J. (2010). Resilience in families with an autistic child. Education and Training in Autism and Developmental Disabilities, 45(3), 347-355.

Green, S. E. (2003) “'What do you mean "what's wrong with her?": stigma and the lives of families of children with disabilities', Social Science E Medicine, $57(8), 1361-1374$.

Gupta, A., \& Singhal, N. (2005). Psychosocial support for families of children with autism. Asia Pacific Disability Rehabilitation Journal, 16(2), 62-83.

Hall, H \& Graff, C. (2011). The Relationships among Adaptive Behaviors of Children with Autism, Family Support, parenting Stress, and Coping. Issues in Comprehensive Pediatric Nursing, 34 (1), 4- 25.

Hanafi, A. (2007) Families of children with special needs: Teachers and parents guide. Dar Elelm w Aleman. Cairo. Egypt.

Hastings, R. (2003). Child Behavior Problems and Partner Mental Health as Correlates of Stress in Mothers and Fathers of Children with Autism. Journal of Intellectual Disability Research. 47 (4/5) 231-237.

Hughes, T., \& Watson, S. L. (2018). Sibling Relationships in Families of Children with Autism Spectrum Disorder, Fetal Alcohol Spectrum Disorder, and Down Syndrome: A Comparison Study. Journal on Developmental Disabilities, 23(2), 117-117.

Hyassat, M. (2013). Jordanian Parents of Young Children with Disabilities Perspectives on Care, Coping, and Service Provision. Scholars' Press.

Hyassat, M. A., Akhayat, M. M., \& Alzyoud, N. (2015). Development of a Scale for Measuring Parental Satisfaction with Services Available for Disabled Children in Jordan. International Journal of Special Education, 30(1), 3744 .

Ilias, K., Cornish, K., Kummar, A. S., Park, M. S. A., \& Golden, K. J. (2018). Parenting stress and resilience in parents of children with autism spectrum disorder (ASD) in Southeast Asia: a systematic review. Frontiers in psychology, 9, 1-14.

Jellett, R., Wood, C., Giallo, R. \& Seymour, M. (2015). Family Functioning and Behavior Problems in Children with Autism Spectrum Disorders: The Mediating Role of Parent Mental Health. Clinical Psychologist, 19 (1), 39-48.

Jones, L, Hasting, R., Totiski, V., Keane, L. \& Rhule, N. (2014). Child Behavior Problems and Parental Well-being in Families of Children with Autism: The Mediating Role of Mindfulness and Acceptance. American Journal on Intellectual and Development Disabilities, $119(2), 171-185$.

Kelly, A, Garnett, M, Attwood, T \& Peterson, C. (2008). Autism Spectrum Symptomatology in Children: The Impact of Family and Peer Relationships. Journal of Abnormal Child Psychology, 36 (7), 1069-1081.

Kersh, J., Hedvat, T. T., Hauser-Cram, P., \& Warfield, M. E. (2006). The contribution of marital quality to the wellbeing of parents of children with developmental disabilities. Journal of Intellectual Disability Research, 50(12), $883-893$.

Lee. G (2009). Parents of Children with High Functioning Autism: How Well Do They Cope and Adjust. Journal Development Physiology Disabilities 21, 93-114.

Li, J., Vestergaard, M., Obel, C., Christensen, J., Precht, D. H., Lu, M., \& Olsen, J. (20o9). A nationwide study on the risk of autism after prenatal stress exposure to maternal bereavement. Pediatrics, 123(4), 1102-1107.

Luterman, D. (2004).Counseling Families of Children with Hearing Loss and Special Needs. Journal of the Volta Review, (14), 215-220.

Malijaars, J., Boonen, H., Lambrechts, G., Leeuwen, K. \& Noens, I. (2014). Maternal Parenting Behavior and Child Behavior Problems in Families of Children and Adolescents with Autism Spectrum Disorder. Journal of Autism Development Disorder, 44: 501-512. 
Malkosh, R., \& Yahya, K. (1995) Psychological Stress and Social Support among Parents of Disabled Children in Amman. Dirasat: Educational Sciences, 22(5), 2348-2348.

Mascha, K., \& Boucher, J. (2006). Preliminary investigation of a qualitative method of examining siblings' experiences of living with a child with ASD. The British Journal of Development Disabilities, 52(102), $19-28$.

Matter, K. J. (2006). Parent Needs Assessment: a tool to support the transition into special education for children with autism and their families (Doctoral dissertation, Humboldt State University).

McLinden, S. (1990). Mothers' and fathers' reports of a young child's effects with special needs on the family. Journal of Early Intervention, 14(3), 249-259.

Nora, G.(1991). A gender analysis of autistic boys, social adjustment and depression, unpublished doctoral dissertation, Canada university of Toronto.

Obrien, S. (2013). The Influence of Daily Stressors, Severity of Behavior Problems, Uncertainty, and Coping Strategies, and Family Adaptation in Families of Adolescents with Autism Spectrum Disorders. Doctoral Dissertations, The Catholic University of America.

Omar, T. E., Ahmed, W. M., \& Basiouny, N. S. (2017). Challenges and adjustments of mothers having children with autism. Alexandria Journal of Pediatrics, 30(3), 120-129.

Padden, C., \& James, J. E. (2017). Stress among parents of children with and without autism spectrum disorder: a comparison involving physiological indicators and parent self-reports. Journal of developmental and physical disabilities, 29(4), 567-586.

Padden, C., \& James, J. E. (2017). Stress among parents of children with and without autism spectrum disorder: a comparison involving physiological indicators and parent self-reports. Journal of developmental and physical disabilities, 29(4), 567-586.

Phetrasuwan, S \& Miles, M. (2009). Parenting Stress in Mothers of Children with Autism Spectrum Disorders. JSPN, $14(3), 157-165$.

Rao, P. A., \& Beidel, D. C. (2009). The impact of children with high-functioning autism on parental stress, sibling adjustment, and family functioning. Behavior modification, 33(4), 437-451.

Rogers, C. (2007) 'Disabling a family? Emotional dilemmas experienced in becoming a parent of a child with learning disabilities', British Journal of Special Education,34(3), 136-143.

Rozonova, R.G. (2008). Psychological Counseling and Psychotherapy of Families with Autistic Children. Psychological SciencesE Education, 4(1) 91-100.

Sabah, A., \& Mansory, A. (2013) Psychological Stresses among Parents of Disabled. Educational and Psychological Dirasat:1 (1), 8-27.

Sevim, B. (2007). the Effects of Stress management Program for Mothers of Children with Autism, Doctoral Dissertations, Middle East Technical University.

Siklos,S. \& Kerns, K. (2006). Assessing Need for Social Support in Parents of Children with Autism and Down syndrome. Journal 36(7), 921-933.

Sikora, D., Moran, E., Orlich, F., Hall, T., Kovacs, E., Delahaye, J., Clemons, T. \& Kuhlthau, K. (2013). The Relationship between Family Functioning and Behavior Problems in Children with Autism Spectrum Disorders. Research in Autism Spectrum Disorders, 7(2), 307-315.

Thompson S. (2018). The current situation of persons with disabilities in Jordan. K4D Helpdesk Report. Brighton, UK: Institute of Development Studies. Available online: https://assets.publishing.service.gov.uk/media /5bb22804ed915d258ed26e2c/Persons_with_disabilities_in_Jordan.pdf (accessed on 24/10/209).

Venkatesh Kumar, G. (2008). Psychological stress and coping strategies of the parents of mentally challenged children. Journal of the Indian Academy of Applied Psychology, 34(2), 227-231.

Wiggins, L. D., Rice, C. E., Barger, B., Soke, G. N., Lee, L. C., Moody, E., \& Levy, S. E. (2019). DSM-5 criteria for autism spectrum disorder maximizes diagnostic sensitivity and specificity in preschool children. Social psychiatry and psychiatric epidemiology, 54(6), 693-701.

Yahya, K. (2009) Counseling Families of Children with Disabilities. Dar Al-Feker. Amman. Jordan.

Zaareer, A. (2009). Psychological Stress Sources among Parents of Autistic Children in Jordan and Coping styles with them concerning some Variables. Unpublished dissertation. Amman Arab University. 